\title{
Overcoming the euro crisis: medium and long term economic perspective
}

\author{
Werner Röger $^{1}$ • Paul J. J. Welfens ${ }^{2} \cdot$ Holger Wolf ${ }^{3}$
}

Published online: 26 January 2016

(C) Springer-Verlag Berlin Heidelberg 2016

This special issue is based on a joint international workshop on "Overcoming the Euro Crisis: Medium and Long Term Economic Perspectives” exploring key issues relating to European integration, euro crisis dynamics and international policy cooperation. The workshop was held at the Industrieclub Düsseldorf on March 27-28, 2014 and organized by the bdvb Research Institute, Düsseldorf and the European Institute for International Economic Relations (EIIW at the University of Wuppertal); both institutes under the presidency of Paul Welfens.

The transatlantic banking crisis followed by the sovereign debt crisis came as a major economic shock to the EU and to the Eurozone in particular. Almost a decade later, the fundamental challenges of high youth unemployment, deflationary pressure and rising debt-GDP ratios remain pressing across much of the Eurozone. In its aftermath, lively debates focussed on identifying causes and challenges including institutional shortcomings. The crisis, alongside substantial divergences of both views and economic performance indicators across Eurozone member states, have even led some observers to question the viability of the monetary integration process.

Yet, while the crisis exposed serious shortcomings in institutional design, predictions of inevitable collapse have to date proved unfounded. Indeed, Eurozone membership has expanded since 2008. Nor have policy-makers been un-responsive. While some politically sensitive issues - notably relating to risk-sharing arrangements with fiscal implications for the member states - remain unaddressed, the institutional framework has been substantially strengthened, particularly in fiscal governance and banking supervision. A glass half-full perspective suggests an - admittedly painfully slow -

Paul J. J. Welfens

Welfens@uni-wuppertal.de

1 European Commission, Brussels, Belgium

2 European Institute for International Economic Relations, University of Wuppertal, Wuppertal, Germany

3 Georgetown University, Washington, DC, USA 
emergence of a stronger, more dynamic and more coherent economic and political entity in Europe.

The papers in this volume take up several of the challenges raised by the crisis in greater detail, contributing to the ongoing debates. The first contribution, by Hans Dietrich and Joachim Möller, analyses the specific structure and causes of youth unemployment in Europe. Rising sharply from below $4.2 \mathrm{~m}$ in 2007 to more than $5.6 \mathrm{~m}$ in 2013 (reflected in a rise of the youth unemployment rate from 15.5 to $25.5 \%$ ) youth unemployment has - often lasting - effects on individuals and raises significant societal concerns, giving particular urgency to both the diagnosis of causes and the formulation of effective policy measures.

The second contribution, by Kieran Mc Morrow, Fabrice Orlandi, Rafal Raciborski, Werner Roeger, Valerie Vandermeulen, Jan in 't Veld and Lukas Vogel, considers medium-term economic dynamics, analysing the euro area's growth over the last 1520 years and providing a medium term outlook. The paper concludes that in a "no policy change" scenario economic growth will be subdued, reflecting the influence of weak pre-crisis trends (most notably for TFP growth), the ongoing negative fallout from the financial crisis and the emerging drag on growth emanating from ageing populations.

The third paper, by Manfred Kremer, analyses a macro-financial AR model for the euro area that includes - apart from conventional measures of output, inflation and monetary policy - the CISS index, a composite indicator of systemic financial stress as well as total assets of the ECB balance sheet, capturing the stance of unconventional monetary policy. This new index works well and thus recommends itself for use by policymakers and economic actors.

The forth contribution, by Holger Wolf, takes a closer look at adjustment under fixed exchange rates by exploring the experience of the Baltic States, adopting de jure or de facto currency boards in the early 1990s and experiencing both home-made and external volatility before successfully exiting into the Eurozone between 2011 and 2015.

The fifth paper, by Paul Welfens, explores the challenges raised by the euro crisis and the subsequent policy response - notably the ECB's quantitative easing policy and emphasizes the need for a better understanding of the key issues of Eurozone stabilization and economic benefits from monetary integration. The latter aspect is explored through an economic welfare analysis incorporating the benefits of the euro's reserve currency position within a neoclassical growth model with seigniorage based on international reserve holdings.

The sixth contribution, by Bernd Hayo and Florian Neumeier, explores public opinion on the adoption of balanced budget rules, one of the core responses to the crisis. Their findings, based on a survey of 2000 representatively chosen German citizens, suggest that $61 \%$ of the population support the debt brake, whereas only $8 \%$ oppose it. However, approval rates differ notably among various subgroups of the population.

The last contribution by Holger Schmieding is entitled "Searching for the lender of last resort". Schmieding argues that a pragmatic view is adequate and that the ECB should consider options for innovative monetary policy.

We hope that this volume contributes to a better understanding both of the monetary and real effects of banking crises and currency integration and of the policy options to 
address the resulting challenges. We are grateful to conference participants for many helpful comments. Special gratitude goes to the bdvb (Bundesverband der Volks- und Betriebswirte), Germany's leading association of professional economists and managers. We should also like to thank the staff of the bdvb and the EIIW, particularly Ms. Christina Wiens, who organized a superb event in Düsseldorf. Not least, editorial assistance by David Hanrahan, EIIW, is gratefully acknowledged.

Brussels, Düsseldorf/Wuppertal and Washington DC

January 2016

Werner Röger, Paul JJ Welfens and Holger Wolf 